\title{
Management of Fulminant Hepatitis B
}

\author{
Philippe Ichai ${ }^{1,2,3} \cdot$ Didier Samuel $^{1,2,3}$ \\ Published online: 4 June 2019 \\ (C) Springer Science+Business Media, LLC, part of Springer Nature 2019
}

\begin{abstract}
Purpose of Review Acute HBV infection and acute exacerbations of chronic HBV infection can cause acute liver injury (ALI) or fulminant hepatitis $(\mathrm{FH})$. At this stage, spontaneous survival is poor, less than $25 \%$. The purpose of this review is to provide an overview of specific management of patients with HBV-ALI/FH.

Recent Findings Acute HBVinfection and acute exacerbations of chronic HBVinfection can cause acute liver injury (ALI) or fulminant hepatitis (FH). Spontaneous survival at this stage is poor. It is urgent to distinguish between these two entities so that antiviral therapy can be initiated rapidly. Although the indications for antiviral therapy are clear for HBV reactivation, there is no true consensus regarding ALI/FH related to acute HBV infection. The global management of HBV-related FH does not differ from that implemented for other causes of $\mathrm{FH}$, i.e. close cardiorespiratory and neurological monitoring, treatment with acetylcysteine, organ support in the event of organ failure (haemodynamic, renal, respiratory) and albumin dialysis. Liver transplantation remains the only alternative when certain criteria for a poor prognosis are met. A recurrence of HBV infection on the graft can be prevented post-transplant by the administration of HBIG and antiviral therapy for HBV, the modalities varying depending on the risk of recurrence.
\end{abstract}

Keywords Acute liver failure · Fulminant hepatitis $\cdot \mathrm{HBV}$ infection $\cdot$ Acute exacerbation $\cdot$ Chronic HBV infection $\cdot$ Management . HBV antiviral therapy

\section{Introduction}

The epidemiology of HBV hepatitis has changed considerably during the past 10 years because of global vaccine policies, the development of effective antiviral agents against hepatitis B and the serological screening of populations at risk. However, despite this downturn, HBV remains a major cause of

This article is part of the Topical Collection on Intra-Abdominal Infections, Hepatitis and Gastroenteritis

Didier Samuel

didier.samuel@aphp.fr

Philippe Ichai

philippe.ichai@aphp.fr

1 Centre Hépato-Biliaire, Liver Intensive Care Unit, AP-HP Hôpital Paul-Brousse, 12 Avenue Paul Vaillant Couturier, 94804 Villejuif, France

2 INSERM, Unité 1193, Université ParisSud, Paris-Saclay, 94800 Villejuif, France

3 DHU Hepatinov, 94800 Villejuif, France fulminant hepatitis (FH). It may cause between 5 and $18 \%$ of cases of fulminant hepatitis (FH) in Europe, between 13 and $15 \%$ in Bangladesh and India and $22 \%$ of FH cases in Sudan. In the USA, HBV only accounts for $7 \%$ of FH cases. In France, HBV was the second most common cause of FH requiring patients to be listed for emergency LT between 1998 and 2010 (12.7\%), after paracetamol (22.2\%) [1].

HBV-related FH can occur in patients who have had no previous contact with the virus (primary infection) and in those affected by chronic HBV infection. In this latter case, ALF is due to an exacerbation (flare-up) of chronic HBV (reactivation), either spontaneously or after the initiation or discontinuation of immunosuppressive therapy.

While acute HBV infections are tending to diminish, reactivations of $\mathrm{HBV}$ are increasing because of the numerous immunosuppressive therapies initiated in patients presenting with solid or haematological malignant tumours [2]. This risk is even higher in regions where $\mathrm{HBV}$ is endemic [3]. The rule is therefore to systematically screen patients infected by HBV who are risk of its reactivation before they start any chemotherapy or other immunosuppressive therapy. The course of hepatitis B differs as a function of age; a risk of chronicity has 
been shown to be very high in the event of neonatal infection $(>90 \%)$ and diminishes markedly in non-immunosuppressed young adults $(<5 \%)[4]$. However, there is a much higher risk of fulminant $\mathrm{HBV}$ in young adults.

HBV infection can display several clinical phenotypes. It may be asymptomatic or paucisymptomatic, without or without elevated transaminases, or on the contrary cause an acute liver injury (ALI) or fulminant hepatitis.

\section{Definition of Acute Liver Injury, Acute Liver Failure}

Acute liver injury (ALI) is defined by an INR higher than 1.5 without associated hepatic encephalopathy.

Fulminant hepatitis (FH) or acute liver failure (ALF) is defined by an INR $>1.5$ and the presence of hepatic encephalopathy but the absence of chronic, underlying (or prior) disease. The time to onset of the disease should be less than 26 weeks [5]. FH HBV is more frequent in hyperacute ALF (jaundice-encephalopathy for less than 7 days) or ALF (jaundice-encephalopathy for less than 2 months) than in subacute ALF (jaundice-encephalopathy $>2$ months).

An acute exacerbation of chronic HBV infection (reactivation) may develop in the form of fulminant hepatitis (rapidity of its course, multi-organ failure, cerebral oedema, etc.). As a result, even though this entity does not form part of the definition of ALF or FH, it is similar because of its progressive profile.

A reactivation of $\mathrm{HBV}$ is defined by a rise in HBV DNA levels of more than $1 \log$ in a patient who had previously presented with positive HBV DNA, or the reappearance of HBV DNA in a patient whose viral load was previously negative.

\section{Impact of HBV Pathogenicity on Therapeutic Strategy}

In severe forms such as ALI and FH, the decision to treat a patient or not must be taken rapidly in order to increase the chances of a spontaneous cure. It is therefore urgent to make a distinction between these two entities - acute HBV infection and $\mathrm{HBV}$ reactivation - because although their progressive profiles have some similarities, their management differs.

\section{Primary (or Acute) HBV Infection}

Exposure to the hepatitis B virus causes an acute infection that resolves spontaneously in most patients with a strong immune status. This response takes the form of acute hepatitis. ALI or FH may be the result of an exaggerated immune response.

At an early stage of the infection, HBV does not stimulate the innate immune system which recognizes pathogen-associated molecular patterns. At a late stage, an appropriate cellular immune response and a large number of effector molecules are induced at the same time as the appearance of antibodies. The elimination of HBV starts several weeks before the onset of disease through a $\mathrm{T}$ cell dependent non-cytolytic mechanism. It is only later that the cytolytic immune response appears and generates the symptoms of hepatitis. During this phase, numerous cytolytic CD8 cells are present in the liver and will react with multiple epitopes, eliminating the virus by destroying infected cells. The activated function of CD8+ T cells is suppressed by a rise in arginase levels which aims to limit the amount of the liver that will be damaged by them in patients with acute HBV infection [6]. Furthermore, soluble Fas may play a role in the onset of fulminant hepatitis. Soluble Fas antigens are present at high levels in patients presenting with this condition, which suggests their involvement in liver damage and that apoptosis is the principal mechanism underlying this damage [7].

Therefore, an absence of the virus, or its presence at very low levels, at the time when the disease manifests itself, constitutes arguments against antiviral therapy for acute HBV infection. In some cases, HBsAg is no longer detectable at the time of admission for HBV-ALF. In addition, those patients who survive HBV-ALF without liver transplantation will not evolve to chronic hepatitis and will become $\mathrm{HBsAg}$ negative with the appearance of anti-HBsAb in the serum.

The severity of acute HBV infection is also linked to certain characteristics of the virus itself, such as the $\mathrm{D}$ genotype, $\mathrm{Bj}$ genotype, viral delta co-infection, or viral mutations in the B virus (precore mutations) [8-10].

\section{HBV Reactivation}

The clearance rate of acute HBV infection is estimated at between 90 and $97 \%$ in the adult population. The clearance of HBsAg was seen to reach more than $99.5 \%$ in two studies. This difference resides in the patient's status regarding $\mathrm{HBe} A g$ and precore mutants [11-13].

An acute exacerbation of chronic HBV infection may take the form of ALF. Covalently closed circular DNA (HBV cccDNA) is the principal model for the transcription of viral mRNAs. It persists in the liver even if the HBV infection is controlled (e.g. HBs-Ag negative). HBV DNA may also persist in the liver as integrated HBV DNA. A rapid increase in HBV replication from a low level is the principal cause (as reflected by HBV DNA, anti-HBcIgM, HBeAg) of HBV reactivation. During this phase, transaminase levels rise, jaundice appears and the HBV viral load starts to fall. The first episode of an exacerbation of chronic HBV may occur during different phases of this infection: the immune-tolerant phase, immune-active phase, low-replication phase or resolved phase. An increase in the response of $\mathrm{T}$ cells against $\mathrm{HBeAg}$ and $\mathrm{HbcAg}$ occurs during the early stages of an acute exacerbation (acute flare-up) and declines after recovery from the acute exacerbation and HBeAg seroconversion [14]. Spontaneous flare-ups mainly occur in HBeAg-negative patients.

The risk of reactivation depends on the underlying disease that required immunosuppressive therapy (lymphoma, solid 
tumour, systemic disease, inflammatory bowel disease, immunosuppressive therapy to prevent rejection, etc.), the level of $\mathrm{HBV}$ replication at baseline, the presence of $\mathrm{HBeAg}$, the genotype of the $\mathrm{B}$ virus (non-A genotype), co-infection with another virus (A, E, C, delta, HIV) and the type of immunosuppression (anti-TNF-alpha, corticosteroids, anti-CD20 Ab, etc.). When immunosuppression is withdrawn, immune restoration is followed by the rapid destruction of infected hepatocytes that may also be responsible for ALF (or chronic hepatitis or cirrhosis). The reactivation of HBV during chemotherapy occurs in patients who are HBsAg-positive as well as antiHBc-positive and HBsAg negative.

\section{Risk Factors for Developing FH-HBV}

ALF due to HBV occurs in less than $1 \%$ of jaundiced patients with HBV hepatitis. The concomitant use of paracetamol, methamphetamine or alcohol may be predisposing factors (or risk factors) for developing fulminant hepatitis B ( $p=$ 0.08 ) [15]. Furthermore, patients presenting with genotype D have a greater risk of developing ALF (32\% vs 16\%) [9]. High levels of HBV DNA, B1/Bj subgenotypes or A1762T/ G1764A, G1896A, G1899A and A2339G mutations are found more frequently in patients with fulminant rather than non-fulminant presentations.
The survival rate without transplantation of patients with HBV-related ALF is lower than 25\% [16]. The disease course is rapid, in the form of either hyperacute or acute liver failure.

The risk of cerebral oedema in patients presenting with HBV-ALF has been shown to be higher than in those presenting with subacute liver failure [17].

\section{Management of Fulminant Hepatitis B (Tables 1 and 2)}

\section{A Diagnosis of ALF Versus a Reactivation of Chronic HBV Infection}

It may be difficult to distinguish between acute HBV infection and reactivation of the virus.

Clinical Diagnosis The usual clinical pictures of these two presentations are quite similar: the onset of jaundice and marked cytolysis, sometimes preceded by a prodrome. If signs of chronic disease are present, a diagnosis of HBV reactivation may be simple. The clinical context (recent contact with a new partner, recent immunosuppressive therapy) and personal or family history (previous blood transfusions, known history of HBsAg) are key elements that enable the differentiation of primary infection and

Table 1 Diagnosis of ALF versus reactivation (flare-up or exacerbation) of chronic hepatitis B

\begin{tabular}{|c|c|c|}
\hline & ALF & HBV reactivation \\
\hline Clinical context & $\begin{array}{l}\text { - No history of chronic liver disease } \\
\text { - Recent contact with a new partner }\end{array}$ & $\begin{array}{l}\text {-Family history of chronic HBV disease } \\
\text {-History of blood transfusions } \\
\text {-Known chronic liver disease. } \\
\text {-Known HBsAg } \\
\text {-Organ transplantation, bone marrow graft, HIV } \\
\text {-Recent immunosuppressive therapy/immunomodulator } \\
\quad \text { (anti-TNF alpha, rituximab, etc.) } \\
\text { - Discontinuation of anti-HBV treatment }\end{array}$ \\
\hline Clinical presentation & Jaundice & Jaundice \\
\hline Ultrasound & - No ultrasound signs of chronic liver disease & $\begin{array}{l}\text { - Hepatomegaly, } \\
\text { - Splenomegaly, } \\
\text { - Ascites }\end{array}$ \\
\hline Biochemistry & $\begin{array}{l}\text { - ALT, AST > 1000-2000 IU/L } \\
\text { - Bilirubin } \uparrow \\
\text { - GGT } \uparrow\end{array}$ & $\begin{array}{l}-\mathrm{ALT}, \mathrm{AST}>1000-2000 \mathrm{IU} / \mathrm{L} \\
\text { - Bilirubin } \uparrow \\
\text { - GGT } \uparrow \\
-\alpha \mathrm{FP} \uparrow\end{array}$ \\
\hline $\begin{array}{l}\text { Virological markers } \\
\text { (serology, HBV viral load) }\end{array}$ & $\begin{array}{l}\text { - Anti-HBc IgM +++ (> 1:1000) } \\
\text { - HBsAg + (but may be negative) } \\
\text { - HBeAg + } \\
\text { - HBV-DNA slightly elevated }\end{array}$ & $\begin{array}{l}\text { - Anti-HBc IgM }+(<1: 1000) \\
-\mathrm{HBsAg}+(\text { but may be negative) } \\
-\mathrm{HBeAg}+ \\
\text { - HBV-DNA }+++ \\
\text { - Combination of low or undetectable anti-HBc } \\
\quad \text { IgM Bc plus HBV DNA }>\log 10 \mathrm{IU} / \mathrm{mL}\end{array}$ \\
\hline HBV viral genotype & $\begin{array}{l}\text { - Genotype D } \\
\text { - B1/Bj subgenotypes } \\
\text { - A1762T/G1764A, G1896A, G1899A } \\
\quad \text { and A2339G mutations }\end{array}$ & \\
\hline
\end{tabular}

$A L F$ acute liver failure 
Table 2 Management of HBV-related ALI/FH

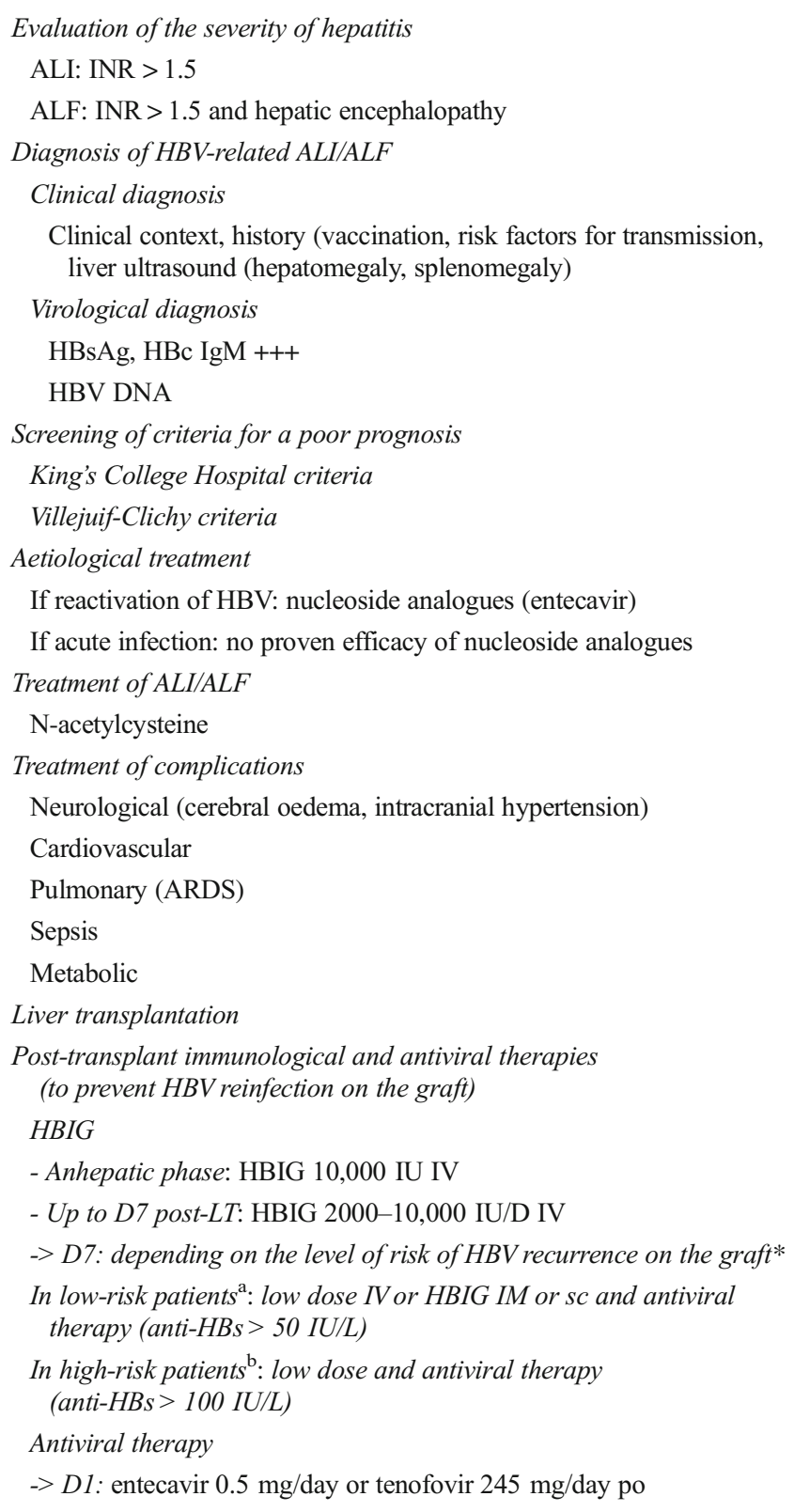

*Low- or high-risk patients

${ }^{\text {a }}$ Undetectable HBV DNA levels, HBeAg negative, fulminant hepatitis B, HDV coinfection ${ }^{48}$

${ }^{\mathrm{b}}$ Detectable HBV DNA levels, HBeAg positive, presence of drug-resistant HBV, HIV coinfection, high risk of HCC recurrence, poor compliance with antiviral therapy ${ }^{48}$

HBV reactivation. The presence of ascites or splenomegaly (clinical and/or determined by ultrasound) is also suggestive of HBV reactivation. Splenomegaly will be more common in patients presenting with HBV reactivation than in those with an acute HBV infection.

As a general rule, liver tests provide little information on the mechanism underlying the infection [18]. Bilirubin levels may be higher in patients presenting with HBV reactivation than in those with a primary infection [19]. Alpha feto-protein (AFP) levels were found to be less frequently elevated in patients presenting with ALF $(26.1 \%)$ than in those experiencing an HBV reactivation $(63.2 \%)$, where the levels were higher $(171.7 \mathrm{ng} / \mathrm{mL}$ vs $13.9 \mathrm{ng} / \mathrm{mL}$ ) [20].

Virological Diagnosis It is mainly a virological diagnosis that can make a distinction between reactivation and primary HBV infection. A diagnosis of acute HBV infection is based on the detection of HBc IgM, HBsAg and HBV DNA.

Anti-HBc IgM levels are strongly positive in the event of primary HBV infection. An anti-HBc IgM titre of $>1: 1000$ is in favour of a primary infection, while an anti-HBc IgM level $<1: 1000$ is more suggestive of a reactivation [18]. An anti$\mathrm{HBc}$ IgM titre $>1: 10,000$ was seen to have a sensitivity of $96.2 \%$ and specificity of $93.1 \%$ in patients presenting with an acute HBV infection [20].

HBsAg is an unreliable diagnostic marker in the event of ALF. It may be undetectable at the time of diagnosis. In the series studied by Dao et al., it was only present in $20 \%$ of cases, which was due to the massive clearance of infected hepatocytes in the event of primary acute HBV infection [21].

HBV DNA levels can also differentiate reactivation from acute HBV infection. They are lower in patients presenting with primary HBV ALF. In Dao's series, HBV DNA levels were found to be lower than $3.9 \log 10 \mathrm{IU} / \mathrm{L}$ in patients presenting with ALF at admission, versus $5.2 \log 10 \mathrm{IU} / \mathrm{mL}$ in those with HBV reactivation. The median viral loads at admission in acute HBV infections were $3.9(0-8.1) \log 10 \mathrm{IU} /$ $\mathrm{mL}$ versus $5.2(2.0-8.7) \log 10 \mathrm{IU} / \mathrm{mL}$ in the case of an exacerbation of chronic HBV infection $(p<0.025)$ [21].

$\mathrm{HBeAg}$ is found in patients presenting with both primary $\mathrm{HBV}$ infection and viral reactivation. However, the titre is lower in patients with HBV-ALF [20].

In summary, a combination of viral markers can help to distinguish between HBV ALF and reactivation. A low or undetectable level of anti-HBc IgM and a high HBV viral load $(>\log 10 \mathrm{IU} / \mathrm{mL}$ ) may be suggestive of reactivation rather than acute HBV [21].

\section{Determination of Superinfection}

A flare-up of chronic HBV infection can occur following a superinfection by another hepatotropic virus such as A, C, E or delta. These viruses should always be ruled out when there is a suspected flare of chronic HBV infection. Some studies have shown that mortality was higher in the case of superinfection with HAV [22] and that the risk of HBV reactivation was greater in the event of superinfection with HEV [23]. Superinfection with the delta virus may cause a severe exacerbation of HBV [24]. 


\section{Antiviral Therapy}

When antiviral therapy is decided upon at the ALI or FH stage, it should be initiated rapidly in a specialized centre with access to transplantation. This therapy should never delay the timing of transplantation.

ALF In theory, the initiation of antiviral therapy in patients presenting with acute HBV infection should shorten the duration of the disease, reduce the risk of progression of HBV-ALI towards ALF, and diminish the risk of graft infection by HBV by lowering the HBV viral load or even rendering it negative, if liver transplantation proves necessary.

There is no clear consensus regarding the usefulness of antiviral therapy in the context of HBV-ALF. This is probably because a rapid reduction in HBV-DNA replication is an argument against the use of an antiviral agent in patients presenting with ALF where the HBV viral load is low [25]. No controlled or randomized studies have yet proved an increase in the survival of patients treated with an antiviral agent who presented with HBV-related ALF. A multicentre study compared 17 patients with ALI or ALF treated with lamivudine versus an historical control cohort. The survival of patients without transplantation was significantly higher in patients treated with lamivudine than in the control arm (82.4\% versus $20 \%)$. At the initiation of lamivudine therapy, seven patients presented with hepatic encephalopathy (grade 1: five; grade 4: two). The mean values $( \pm \mathrm{SD})$ at admission for INR, bilirubin, ALT and lactates in the treated and non-treated patients (historical controls) were 4.15 (2.19), $247.0 \mu \mathrm{mol} / \mathrm{L}$ (133.7), 3022.7 IU/L (1562.6), $5.1 \mu \mathrm{mol} / \mathrm{L}$ (5.3), 3.91 (1.59), $328.0 \mu \mathrm{mol} / \mathrm{L}(206.7), 1966.2 \mathrm{IU} / \mathrm{L}$ (1374.3) and $5.9 \mu \mathrm{mol} / \mathrm{L}$ (4.9), respectively [26].

Numerous other studies have reported good survival among patients treated with lamivudine. In all cases, antiviral therapy should be initiated early to have the optimum effect. A controlled and randomized study including 71 patients demonstrated that those receiving lamivudine presented with a marked reduction in HBV DNA, but clinical and biochemical improvements (bilirubin, INR, ALT) were similar in the lamivudine and placebo arms [27]. Furthermore, other controlled studies have suggested that lamivudine enabled a significant reduction in mortality among patients presenting with fulminant hepatitis without signs of SIRS (systemic inflammatory response), and thus at an early stage in the disease [28, 29].

Entecavir and adefovir have also been assessed in patients presenting with HBV-induced ALF. During a registry study including 85 patients with HBV-related ALF (acute and reactivation), 61 were identified as having ALF (as opposed to the other patients who presented with an $\mathrm{HBV}$ reactivation). Of these patients, 27 received a nucleotide analogue and 34 were not treated. The NA treatment involved lamivudine, entecavir, tenofovir, lamivudine or adefovir. Both groups of patients were similar in terms of viral load, INR level and the grade of hepatic encephalopathy. There were no differences in overall survival and transplant-free survival between the treated and untreated patients [30].

HBV Reactivation Antiviral therapy with nucleoside analogues is justified by the presence of high HBV replication during the reactivation of a chronic HBV infection. If initiated at an early stage, lamivudine can improve the survival of patients presenting with HBV reactivation, but in patients with low bilirubin levels $(<20 \mathrm{mg} / \mathrm{dL})$ [31] or a MELD score lower than 30 [32]. However, mortality at 3 months remained high during that study $(50.7 \%)$.

Entecavir and tenofovir may be more effective and cause less resistance [33].

Use of a nucleotide analogue (entecavir or lamivudine) significantly reduced viral replication but not survival at 3 months when compared with patients not receiving these analogues (48.5\%, 50.0\% and $40.5 \%$, respectively) [34].

However, a recent controlled and randomized study showed that tenofovir significantly increased 3-month survival (57\% versus $15 \%$ in the placebo arm) [35]. In that study, a reduction of more than $2 \log$ in HBV DNA levels after 2 weeks of treatment was a predictive factor for survival. It is thus now considered standard of care that antiviral therapy with a second generation NA (tenofovir or entecavir) be used in this situation, but $25 \%$ of patients will die without LT despite displaying an adequate virological response [36, 37].

\section{N-Acetylcysteine}

$\mathrm{N}$ acetylcysteine is the antidote to paracetamol (acetaminophen) overdoses. It can even be effective when administered at a late stage after paracetamol ingestion and after the onset of liver damage. NAC is also endowed with antioxidant and immunological properties that may influence the outcomes of patients presenting with non-acetaminophenrelated acute liver failure. During a controlled and randomized study including 173 patents with ALF that was not due to paracetamol, NAC significantly increased transplant-free survival among patients presenting with low-grade hepatic encephalopathy (grades 1 and 2) [38].

\section{Treating the Complications of HBV-ALF}

One of the major complications of ALF is the onset of multiorgan failure. All organs may be affected: the heart (cardiovascular shock), lungs (acute respiratory distress syndrome), kidneys (acute kidney injury), pancreas (pancreatitis), bone 
marrow (pancytopenia of central origin) or adrenal glands (adrenal insufficiency). However, the most specific complication of ALF is the onset of cerebral oedema and intracranial hypertension. Alongside sepsis and multi-organ failure, it is one of the most common causes of mortality in patients with ALF [39].

The management of these complications is relatively similar to that of other critical patients without hepatic disease.

The gravity of neurological complications justifies the close monitoring of hepatic encephalopathy, the determination of clinical signs of cerebral oedema and intracranial hypertension, and the measurement of blood flow velocity and indirectly of intracranial pressure (ICP) using transcranial ultrasound. General measures should be implemented: elevation of the head to $30^{\circ}$, correction of any fever, hyponatremia or hypophosphoremia, intubation and mechanical ventilation in the event of high-grade hepatic encephalopathy (grade 4), maintenance of a mean blood pressure at $>75-80 \mathrm{mmHg}$, and PCO2 at between 34 and $42 \mathrm{mmHg}$. The onset of intracranial hypertension should be treated with osmotherapy (bolus of mannitol or hypertonic saline solution) and optimal sedation.

Moderate hypothermia did not prove its efficacy with respect to ICP and cerebral perfusion pressure during a controlled and randomized study [40]. Nor has artificial liver support demonstrated its usefulness in terms of the survival of patients presenting with fulminant hepatitis. During a controlled, randomized, multicentre study (the FULMAR study), the 6-month survival of patients presenting with ALF and treated using the MARS system was identical to that of patients receiving standard drug therapy [41]. However, it is important to note that the median delay between randomisation and transplantation was short, which could have prevented excluding a beneficial effect of MARS. A recent controlled and randomized study showed that highvolume plasma exchange could significantly increase the overall survival of ALF patients (mostly paracetamol overdose). In addition, among non-transplanted patients, the survival of those treated with high-volume plasma exchange was significantly better than that of patients receiving standard therapy [42].

\section{Liver Transplantation}

The King's College Hospital criteria for a poor prognosis (non-paracetamol) and the Clichy Villejuif criteria are the most widely employed when making liver transplant decisions $[1,43,44]$. These criteria are also applicable to patients with HBV-related ALF. The Clichy-Villejuif criteria had initially been established in a cohort of patients where most presented with fulminant hepatitis B (Table 3). In the series described by Ichai et al., $13 \%$ of patients presenting with HBVrelated ALF died on the waiting list [1]. In the event of ALI/
Table 3 ALF poor prognosis criteria

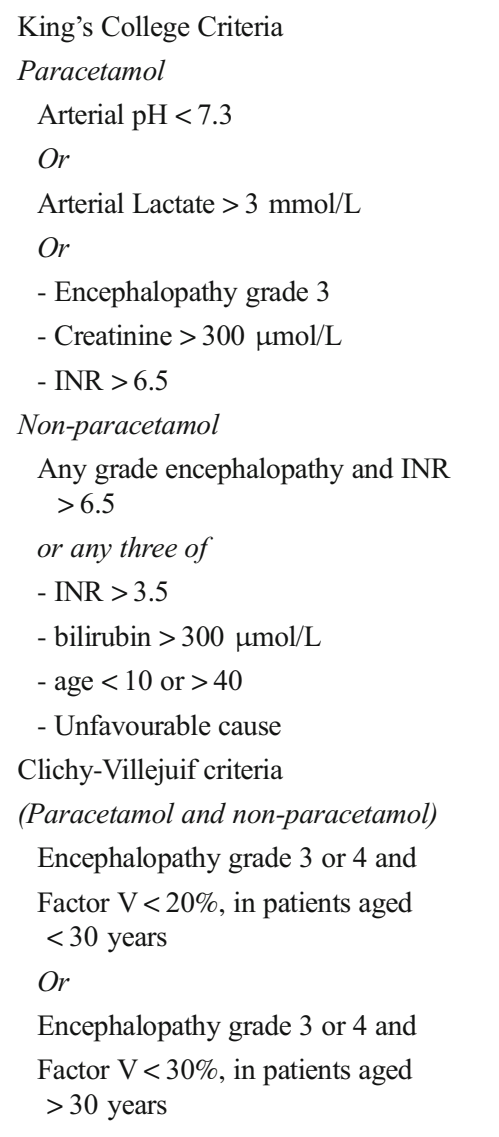

FH related to HBV reactivation, antiviral therapy should be initiated in a specialized unit with access to transplantation in case the patient's state worsens. This treatment should not delay a liver transplant.

In patients presenting with $\mathrm{HBV}$ reactivation that occurs in a context of immunosuppressive therapy for the treatment of cancer, the prospects for liver transplantation remain limited.

\section{Prophylactic Treatment for a Recurrence of HBV Infection on a Graft After Transplantation}

A recurrence of HBV may vary depending on the presentation of the infection. It can reach $67 \%$ in patients transplanted for HBV cirrhosis, $32 \%$ after transplantation for HDV cirrhosis and $17 \%$ after transplantation for fulminant hepatitis.

Prophylaxis with anti-HB immune globulin (HBIG) and antiviral prophylaxis after transplantation reduce the risk of HBV recurrence on the graft [45]. During the anhepatic phase and the 7 days following transplantation, HBIG is given at a high dose, the aim being to neutralize HB antigens. The recurrence of HBV is low in this case. Maintenance therapy is then administered in order to target a defined anti-HB level that decreases over time [46]. Several prophylactic regimens, which vary as a function of mode (IV, IM, SC), frequency of 
administration, dose of anti-HBs and target concentration, have been proposed.

A combination of HBIG and antiviral therapy can reduce the cost and constraints of immunoprophylaxis alone and is more effective. Entecavir and tenofovir plus HBIG may be superior to the combination of HBIG and lamivudine [47, 48]. The recurrence of $\mathrm{HBV}$ is low in patients transplanted for fulminant hepatitis $\mathrm{B}$ and receiving immunoprophylaxis. By contrast, in patients with HBV reactivation, HBV DNA at the time of LT is frequently high and controlling HBV recurrence may be difficult despite adequate immunoprophylaxis against HBV. If possible, the HBV DNA level should be below $10^{5}$ copies $/ \mathrm{mL}$, although it might not be possible to achieve this goal because of the severity of liver failure and the emergency situation.

\section{Conclusion}

A diagnosis of acute HBV infection, or an exacerbation (flareup) of chronic HBV-related FH, should be made rapidly to decide or not to initiate an antiviral therapy. Antiviral therapy should be used in reactivation, but not in acute infection. In all cases, the timing of transplantation should not be delayed when the criteria for LT are met and if there are no contraindications to surgery. The spontaneous prognosis for HBVrelated FH is poor. The global management of these patients presenting with $\mathrm{FH}$ does not differ from that of patients with FH linked to another cause. On the other hand, during the postoperative period, HBIG and antiviral therapy must be instituted in order to prevent a recurrence of HBV on the graft. The methods of administration in this case may vary.

\section{Compliance with Ethical Standards}

Conflict of Interest All authors declare no conflict of interest.

Human and Animal Rights and Informed Consent This article does not contain any studies with human or animal subjects performed by any of the authors.

\section{References}

1. Ichai P, Legeai C, Francoz C, Boudjema K, Boillot O, Ducerf C, et al. Patients with acute liver failure listed for superurgent liver transplantation in France: reevaluation of the Clichy-Villejuif criteria. Liver transplantation. 2015;21(4):512-23.

2. Oketani M, Ido A, Nakayama N, Takikawa Y, Naiki T, Yamagishi $\mathrm{Y}$, et al. Etiology and prognosis of fulminant hepatitis and late-onset hepatic failure in Japan: summary of the annual nationwide survey between 2004 and 2009. Hepatol Res. 2013;43(2):97-105.

3. Oketani M, Ido A, Tsubouchi H. Changing etiologies and outcomes of acute liver failure: a perspective from Japan. J Gastroenterol Hepatol. 2011;26(Suppl 1):65-71.
4. McMahon BJ, Alward WL, Hall DB, Heyward WL, Bender TR, Francis DP, et al. Acute hepatitis B virus infection: relation of age to the clinical expression of disease and subsequent development of the carrier state. J Infect Dis. 1985;151(4):599-603.

5. Polson J, Lee WM. American Association for the Study of liver D. AASLD position paper: the management of acute liver failure. Hepatology. 2005;41(5):1179-97.

6. Sandalova E, Laccabue D, Boni C, Watanabe T, Tan A, Zong HZ, et al. Increased levels of arginase in patients with acute hepatitis B suppress antiviral T cells. Gastroenterology. 2012;143(1):78-87 e3.

7. Rivero M, Crespo J, Fabrega E, Casafont F, Mayorga M, GomezFleitas M, et al. Apoptosis mediated by the Fas system in the fulminant hepatitis by hepatitis B virus. J Viral Hepat. 2002;9(2):10713.

8. Lettau LA, McCarthy JG, Smith MH, Hadler SC, Morse LJ, Ukena $\mathrm{T}$, et al. Outbreak of severe hepatitis due to delta and hepatitis B viruses in parenteral drug abusers and their contacts. N Engl J Med. 1987;317(20):1256-62.

9. Wai CT, Fontana RJ, Polson J, Hussain M, Shakil AO, Han SH, et al. Clinical outcome and virological characteristics of hepatitis Brelated acute liver failure in the United States. J Viral Hepat. 2005;12(2):192-8.

10. Ozasa A, Tanaka Y, Orito E, Sugiyama M, Kang JH, Hige S, et al. Influence of genotypes and precore mutations on fulminant or chronic outcome of acute hepatitis B virus infection. Hepatology. 2006;44(2):326-34.

11. Zhang HW, Yin JH, Li YT, Li CZ, Ren H, Gu CY, et al. Risk factors for acute hepatitis B and its progression to chronic hepatitis in Shanghai, China. Gut. 2008;57(12):1713-20.

12. Kuruuzum Z, Ozgenc O, Havuk A, Coskuner A, Ari A, Celenkoglu $\mathrm{N}$. Rate of chronicity and time of disappearance of HBsAg following acute hepatitis B. Hepatogastroenterology. 2009;56(90):466-9.

13. Tassopoulos NC, Papaevangelou GJ, Sjogren MH, RoumeliotouKarayannis A, Gerin JL, Purcell RH. Natural history of acute hepatitis B surface antigen-positive hepatitis in Greek adults. Gastroenterology. 1987;92(6):1844-50.

14. Tsai SL, Chen PJ, Lai MY, Yang PM, Sung JL, Huang JH, et al. Acute exacerbations of chronic type $\mathrm{B}$ hepatitis are accompanied by increased $\mathrm{T}$ cell responses to hepatitis $\mathrm{B}$ core and e antigens. Implications for hepatitis B e antigen seroconversion. J Clin Invest. 1992;89(1):87-96.

15. Garfein RS, Bower WA, Loney CM, Hutin YJ, Xia GL, Jawanda J, et al. Factors associated with fulminant liver failure during an outbreak among injection drug users with acute hepatitis B. Hepatology. 2004;40(4):865-73.

16. Ostapowicz G, Fontana RJ, Schiodt FV, Larson A, Davern TJ, Han $\mathrm{SH}$, et al. Results of a prospective study of acute liver failure at 17 tertiary care centers in the United States. Ann Intern Med. 2002;137(12):947-54.

17. Bernal W, Auzinger G, Dhawan A, Wendon J. Acute liver failure. Lancet. 2010;376(9736):190-201.

18. Kumar M, Jain S, Sharma BC, Sarin SK. Differentiating acute hepatitis B from the first episode of symptomatic exacerbation of chronic hepatitis B. Dig Dis Sci. 2006;51(3):594-9.

19. Han Y, Yan L, Han G, Zhou X, Hong L, Yin Z, et al. Controlled trials in hepatitis $\mathrm{B}$ virus-related decompensate liver cirrhosis: peripheral blood monocyte transplant versus granulocyte-colonystimulating factor mobilization therapy. Cytotherapy. 2008;10(4): 390-6.

20. Han Y, Tang Q, Zhu W, Zhang X, You L. Clinical, biochemical, immunological and virological profiles of, and differential diagnosis between, patients with acute hepatitis B and chronic hepatitis B with acute flare. J Gastroenterol Hepatol. 2008;23(11):1728-33.

21. Dao DY, Hynan LS, Yuan HJ, Sanders C, Balko J, Attar N, et al. Two distinct subtypes of hepatitis B virus-related acute liver failure are separable by quantitative serum immunoglobulin $\mathrm{M}$ anti- 
hepatitis B core antibody and hepatitis B virus DNA levels. Hepatology. 2012;55(3):676-84.

22. Zachoval R, Roggendorf M, Deinhardt F. Hepatitis a infection in chronic carriers of hepatitis B virus. Hepatology. 1983;3(4):528-31.

23. Kumar M, Sharma BC, Sarin SK. Hepatitis E virus as an etiology of acute exacerbation of previously unrecognized asymptomatic patients with hepatitis B virus-related chronic liver disease. J Gastroenterol Hepatol. 2008;23(6):883-7.

24. Smedile A, Farci P, Verme G, Caredda F, Cargnel A, Caporaso N, et al. Influence of delta infection on severity of hepatitis B. Lancet. 1982;2(8305):945-7.

25. Fong TL, Akriviadis EA, Govindarajan S, Valinluck B, Redeker AG. Serum hepatitis B viral DNA in acute viral hepatitis B. Ann Intern Med. 1989;110(11):936-7.

26. Tillmann HL, Hadem J, Leifeld L, Zachou K, Canbay A, Eisenbach $\mathrm{C}$, et al. Safety and efficacy of lamivudine in patients with severe acute or fulminant hepatitis B, a multicenter experience. J Viral Hepat. 2006;13(4):256-63.

27. Kumar M, Satapathy S, Monga R, Das K, Hissar S, Pande C, et al. A randomized controlled trial of lamivudine to treat acute hepatitis B. Hepatology. 2007;45(1):97-101

28. Yu JW, Sun LJ, Yan BZ, Kang P, Zhao YH. Lamivudine treatment is associated with improved survival in fulminant hepatitis B. Liver Int. 2011;31(4):499-506.

29. Yu JW, Sun LJ, Zhao YH, Kang P, Li SC. The study of efficacy of lamivudine in patients with severe acute hepatitis B. Dig Dis Sci. 2010;55(3):775-83.

30. Dao DY, Seremba E, Ajmera V, Sanders C, Hynan LS, Lee WM, et al. Use of nucleoside (tide) analogues in patients with hepatitis Brelated acute liver failure. Dig Dis Sci. 2012;57(5):1349-57.

31. Chien RN, Lin CH, Liaw YF. The effect of lamivudine therapy in hepatic decompensation during acute exacerbation of chronic hepatitis B. J Hepatol. 2003;38(3):322-7.

32. Sun LJ, Yu JW, Zhao YH, Kang P, Li SC. Influential factors of prognosis in lamivudine treatment for patients with acute-onchronic hepatitis B liver failure. J Gastroenterol Hepatol. 2010;25(3):583-90.

33. Colonno RJ, Rose R, Baldick CJ, Levine S, Pokornowski K, Yu CF, et al. Entecavir resistance is rare in nucleoside naive patients with hepatitis B. Hepatology. 2006;44(6):1656-65.

34. Cui YL, Yan F, Wang YB, Song XQ, Liu L, Lei XZ, et al. Nucleoside analogue can improve the long-term prognosis of patients with hepatitis B virus infection-associated acute on chronic liver failure. Dig Dis Sci. 2010;55(8):2373-80.

35. Garg H, Sarin SK, Kumar M, Garg V, Sharma BC, Kumar A. Tenofovir improves the outcome in patients with spontaneous reactivation of hepatitis B presenting as acute-on-chronic liver failure. Hepatology. 2011;53(3):774-80.

36. Fontana RJ, Hann HW, Perrillo RP, Vierling JM, Wright T, Rakela $\mathrm{J}$, et al. Determinants of early mortality in patients with decompen- sated chronic hepatitis B treated with antiviral therapy. Gastroenterology. 2002;123(3):719-27.

37. European Association for the Study of the Liver. Electronic address eee, European Association for the Study of the L. EASL 2017 clinical practice guidelines on the management of hepatitis B virus infection. J Hepatol. 2017;67(2):370-98.

38. Lee WM, Hynan LS, Rossaro L, Fontana RJ, Stravitz RT, Larson $\mathrm{AM}$, et al. Intravenous $\mathrm{N}$-acetylcysteine improves transplant-free survival in early stage non-acetaminophen acute liver failure. Gastroenterology. 2009;137(3):856-64 64 e1.

39. Bernal W, Wendon J. Acute liver failure. N Engl J Med. 2013;369(26):2525-34.

40. Bernal W, Murphy N, Brown S, Whitehouse T, Bjerring PN, Hauerberg $\mathrm{J}$, et al. A multicentre randomized controlled trial of moderate hypothermia to prevent intracranial hypertension in acute liver failure. J Hepatol. 2016;65(2):273-9.

41. Saliba F, Camus C, Durand F, Mathurin P, Letierce A, Delafosse B, et al. Albumin dialysis with a noncell artificial liver support device in patients with acute liver failure: a randomized, controlled trial. Ann Intern Med. 2013;159(8):522-31.

42. Larsen FS, Schmidt LE, Bernsmeier C, Rasmussen A, Isoniemi H, Patel VC, et al. High-volume plasma exchange in patients with acute liver failure: an open randomised controlled trial. J Hepatol. 2016;64(1):69-78.

43. Bernuau J, Goudeau A, Poynard T, Dubois F, Lesage G, Yvonnet B, et al. Multivariate analysis of prognostic factors in fulminant hepatitis B. Hepatology. 1986;6(4):648-51.

44. Samuel D, Muller R, Alexander G, Fassati L, Ducot B, Benhamou JP, et al. Liver transplantation in European patients with the hepatitis B surface antigen. N Engl J Med. 1993;329(25):1842-7.

45. Cholongitas E, Goulis J, Akriviadis E, Papatheodoridis GV. Hepatitis B immunoglobulin and/or nucleos(t)ide analogues for prophylaxis against hepatitis $\mathrm{b}$ virus recurrence after liver transplantation: a systematic review. Liver transplantation : official publication of the American Association for the Study of Liver Diseases and the International Liver Transplantation Society. 2011;17(10):1176-90.

46. Angus PW, Patterson SJ. Liver transplantation for hepatitis B: what is the best hepatitis B immune globulin/antiviral regimen? Liver transplantation. 2008;14(Suppl 2):S15-22.

47. Cholongitas E, Papatheodoridis GV. High genetic barrier nucleos(t)ide analogue(s) for prophylaxis from hepatitis B virus recurrence after liver transplantation: a systematic review. Am J Transplant. 2013;13(2):353-62.

48. Roche B, Samuel D. Prevention of hepatitis B virus reinfection in liver transplant recipients. Intervirology. 2014;57(3-4):196-201.

Publisher's Note Springer Nature remains neutral with regard to jurisdictional claims in published maps and institutional affiliations. 